\title{
Modeling Hydropower Systems for Training
}

\author{
A. A. Sysoev \\ Department of Hydropower and Renewables \\ Moscow Power Engeneering Instute \\ Moscow \\ sasha_sysoev@mail.ru \\ N. V. Lazareva \\ Department of Hydropower and Renewables \\ Moscow Power Engeneering Instute \\ Moscow \\ lazarevanadya98@yandex.ru
}

\author{
A. A. Proskurina \\ Department of Hydropower and Renewables \\ Moscow Power Engeneering Instute \\ Moscow \\ aproskur6@gmail.com
}

\author{
M. G. Tyagunov \\ Department of Hydropower and Renewables \\ Moscow Power Engeneering Instute \\ Moscow \\ mtyagunov@mail.ru
}

\begin{abstract}
Paper presents the software package that implements the ability to study hydroelectric power systems with complex hydraulic connections, planning long-term regime of hydro power plant with the requirements of water users on the example of the Votkinsk hydroelectric plants, and training for the calculation of the water-energy regime of hydroelectric power. The complex is developed in the high-level Python programming language based on the current requirements specified in the rules for the use of water resources of the Votkinsk reservoir. The calculation in the software package is performed by the direct method. Given that the software package is suitable for both research and training. To improve the quality of the calculation, we consider method of swarm optimization. The complex is planned to be used in the course of laboratory work on the planning of the HPP operation mode.
\end{abstract}

Keywords-hydroelectric power plant, water and energy calculation, training complex, operating mode, optimization methods

\section{INTRODUCTION}

One of the significant shortcomings in the development of the country's scientific and technical potential is the growing gap between academic and university fundamental science. This leads to the dispersion of funds, disunity of scientists, and a decrease in the quality of education.

Many software packages are created to solve a specific problem. In the field of hydropower, each hydroelectric power plant or cascade of plants has its own software package, with its own features and with its own requirements. Most of these systems have been used for a long time and do not contain the latest achievements in the field of software development or in the field of computing optimization, which leads to a large number of papers and dissertations on the optimization of one particular cascade, plant. It affects the quality of training of students in Universities, as you have to choose what to pay more time, to seek guidance on working with complex and due to the narrow specialization, they generally are available only to staff the plant, so the employment in this field have to learn to work with the new software. [1].
With the development of computer technology, training in innovation and teamwork skills has become particularly important in technical education. In interactive technologies, the role of the educator and the trainees is changing, and the role of information is also changing: information becomes not the goal of the educational process, but a means for mastering the actions and operations necessary for innovation [2].

The introduction of computer technologies in the educational process, as well as the saturation of universities with computer technology, significantly weakened the interest in other types of technical means. Recent events in the world have shown that the learning process can be completely built on the basis of computer technologies and the Internet, but at the same time the quality of education deteriorates, students ' attention is lost, and interest in the discipline decreases.

Currently, there are no software packages that allow optimizing water and energy regimes in large hydropower systems with complex hydraulic and electrical connections. The project offers the development of a software package that allows optimizing water and energy regimes in large hydropower systems with complex hydraulic and electrical connections, taking into account the experience of using similar complexes for specific hydro power plant (HPP) cascades and other hydropower complexes. The planned software package can be used both for calculating the waterenergy mode of operation of a separate HPP or pumped storage power plant (PSPP) (or cascade of plants) when planning operational modes, and for performing calculations for research, design, and training purposes [3].

\section{Problem Definition And Problem Statement}

Russian Professional standard 20.007 "Employee for planning modes of hydroelectric power plants/accumulating power plants" formulates the main purpose of the type of professional activity as follows: planning of water-power, electric power and hydrological modes of operation of hydropower facilities, ensuring reliable, uninterrupted and trouble-free operation of equipment and electricity generation [4]. This work is devoted to solving some problems of studying

The investigation was carried out within the framework of the project «Energy effect determination in complex hydropower systems from the construction of new hydropower plants» with the support of a grant from NRU "MPEI" for implementation of scientific research programs "Energy" 
complex hydropower systems, as well as teaching students how to calculate the water-energy regime of HPP operation, which includes the following knowledge, skills and abilities:

- Calculation of the optimal water-energy regime of a plant/cascade of plants;

- Implementation of water management and waterenergy calculations of modes of hydropower installations with reservoirs of different types of river flow regulation;

- Verification of the correctness of the performed calculations, the reliability of the final and intermediate results, ensuring the execution of repeated (verification) calculations, if necessary;

- Carrying out calculations in accordance with the current requirements of scientific and technical achievements, imposed on the results of calculations;

- Search for and use in the work of regulatory and technical documentation.

One of the key factors in the learning process is the feedback from the complex and the student's understanding of what actions he performs, and why he does it this way. The theoretical basis is provided by the university teacher, and the practical one is already a complex, so it is important that the actions performed in the complex do not differ or contradict the theoretical foundations [5].

Since the work involves mathematical modeling of complex hydropower systems, it should imply the necessary functionality that allows you to conduct studies of arbitrary systems with complex hydrological connections, which involve hydroelectric power plants, hydroelectric power plants, pumping plants. The complex should take into account the stochastic nature of river flow and the variability of hydrometric characteristics of watercourses. When conducting the research, the complex's functionality should support various modern methods of optimizing the water and energy regime [6].

\section{IMPLEMENTATION OF THE SOFTWARE PACKAGE ON THE EXAMPLE OF THE VotKINSK HYDROELECTRIC POWER Plant}

The implemented complex is designed for the study of complex hydropower systems. The first step to solving the problems described above is to obtain a solution for the existing hydroelectric system, since the main task in conducting research is to obtain an average long-term output, we can consider as the first stage obtaining electricity generation by direct water-energy calculation for the long-term operation of the plant. The Votkinskaya HPP was taken as an existing hydroelectric facility.

To plan the long - term operation of the Votkinsk hydroelectric power plant, the rules for the use of water resources of the reservoir (hereinafter referred to as the Rules) are used as the main document [7]. The restrictions imposed on the long-term operation of the hydroelectric power plant, which were taken into account in this work, are also described in the rules.
Taking into account the restrictions on the Rules, it is necessary to determine the mode of operation of the hydroelectric power plant for the next year. After receiving mode, possible to say how much electricity it produces hydroelectric power for the year, determine the area of work plants in the annual load chart, schedule repairs and to assess the profit that can be paid to the plant over the next year. Like many plants that are operating power facilities, Votkinskaya HPP operates according to the reservoir's dispatching schedule, that is, a set of certain recommended values that determine the permissible values for the final mark of the reservoir at the end of the period under review, as well as the marks determine the permissible average flow rate of the station for the period under review. Since existing power facilities are most often subjected to research on the optimal use of water resources both by the company itself and by scientists, the availability of a database of existing facilities, their limitations and features of operation will be a useful addition to the tool for the study of complex hydraulic systems [8].

The operation of the hydroelectric power plant and the planning of its operating mode in the presence of the current dispatching schedule, has some features. According to the available initial information, namely, inflow costs, the initial mark set at the beginning of the billing period, the operating zone in the field of the dispatcher schedule and the average flow rate of this zone are determined, then, according to the algorithm presented in [9], the upstream mark at the end of the billing period is determined. The resulting upstream mark is plotted on the dispatch chart, if the final mark does not go beyond the boundaries of the working area and the restrictions imposed by other water users are not violated, then this discharge flow into the downstream is taken as the main one for this calculation interval, the resulting upstream mark becomes the initial mark for the next calculation period.

\section{The Main Functions AND Description OF THE ALGORITHM OF THE PROGRAM}

The current version of the program has the implementation of the water-energy calculation of the Votkinskaya HPP in a direct way, as well as the possibility of optimizing the previously obtained mode using a single optimization function. The program is registered as a computer program No. 2019617976 [10] and is used as a training software at the Department of Hydropower and Renewable Energy Sources of the National Research University Moscow Power Engineering Institute (MPEI). The software package is implemented in the PyQt5 software environment in the Python programming language and is suitable for use in the Windows operating system. In this version of the program, the main attention was paid to the creation and analysis of data obtained on the dispatching schedule of the operating power facility. The main functions used in the software package:

- "Getting source data" - the function processes the values of the flow rate and marks, the data is entered manually for each calculation period, obtaining and accounting for the uncertainty of the flow rate is not included in the current version of the software package; 
- $\quad$ "Creating a graphic scene" - the function is responsible for drawing graphic images on the plotting area. Graphic images include: coordinate grid, dispatch schedule, HPP operation mode, dispatch schedule zones;

- "Calculation of the operating mode" - the main function of the program, which is responsible for processing the input data, obtaining the calculated values, interacting with the functions for drawing the HPP operating mode on the graphic scene and entering the results into the calculation table;

- "Compliance with restrictions" - the function is responsible for displaying information in the text field about non-compliance with imposed restrictions or the intersection of the dispatch schedule;

- "Export results" - the function is responsible for creating a separate Microsoft Excel file and filling it with the results of the performed calculation: calculated parameters and the desired HPP mode;

- "Accounting for restrictions" - the function is responsible for adjusting the imposed restrictions during the calculation;

- "Calculation optimization" - a function for optimizing the obtained mode by the method of swarm optimization, with the publication of the result in Microsoft Excel.

1.

The appearance of the complex window is shown in Figure

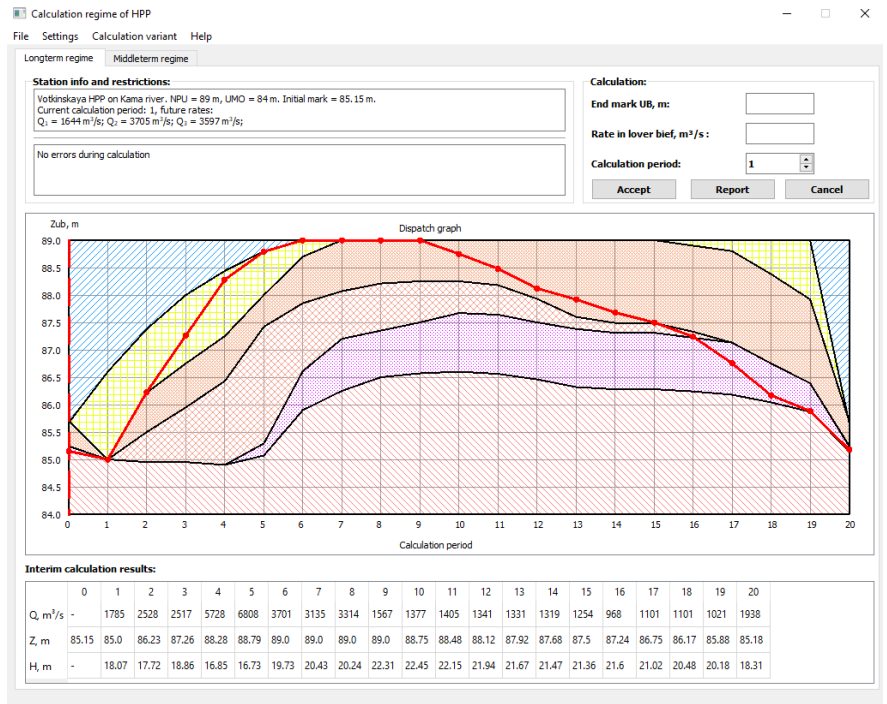

Fig. 1. Appearance of the program complex window with the applied mode (red line)

\section{Optimization OF THE Received Operating Mode}

The mode obtained in the software package by the direct method, i.e., by manually entering the final mark or the average flow rate, should be optimized. A review of modern optimization methods and the work of scientists from different countries [11-15] showed that the most popular optimization methods are:

- Dynamic programming method;

- Nonlinear optimization;

- Swarm optimization;

- Various modifications of the swarm optimization method;

- Heuristic optimization method.

In this paper, the swarm optimization method was chosen as one of the most popular methods for optimizing, managing and processing information. When developing large power and other complex technical systems, problems arise related to the optimization of the interaction of objects and their functioning, which leads to the need to solve optimization problems using effective mathematical optimization methods and modern computer technology. Solving optimization problems of designing and managing technical systems is necessary to improve the technical and economic performance indicators of systems from individual devices to global systems, for example, the energy system of the entire country [16].

Generally, the main goal of optimal operation of a hydropower system is to determine the level of hydrogenation that meets various constraints, including, for example, power grid demand, flood control, water supply, irrigation, ecology, and navigation.

Research on the optimal operation of hydropower systems began in the mid-twentieth century (El-Hawary and Christensen 1979) and was strongly influenced by operational theory and computer science (Yeh 1985; Simonovic 1992; Wurbs 1993). In recent decades, many research and application projects have been proposed to solve this problem, such as linear programming (Yoo 2009), nonlinear programming (Momoh et al. 2012), dynamic programming (Allen and Bridgeman 1986), and coordination of large-scale system decomposition [17].

Since the 1990s, various artificial intelligence and population analysis algorithms have been used for optimal operation of hydropower systems, mainly including artificial neural networks (Labadie 2004), simulated annealing algorithms ( $\mathrm{Fu}$ 2008), honeybee algorithm (Niknam et al. 2011), genetic algorithms (Cinar et al. 2010), differential evolutionary algorithms ( $\mathrm{Lu}$ et al. 2010), and particle swarm optimization (Zhang et al. 2012; Cheng et al. 2009). Among them, dynamic programming is the most popular optimization method for solving problems of optimal operation of largescale cascade hydropower systems [18].

However, the operation of a large-scale cascade hydropower system is a multidimensional, nonlinear, multistage, and strict constraint optimal problem (Barros et al. 2003). The expansion of hydropower systems significantly complicates the hydraulic and electrical connections between cascade power plants. The calculation time during the solution process will increase with the number of installations and the number of constraints. 
PSO (particle swarm optimization), first introduced by Eberhart and Kennedy (1995), is one of the modern natural algorithms. As a method of population optimization, all individuals, called particles, change their position with the help of information about the environment. In the PSO model, the particles fly in a valid space to find optimal solutions. During the flight, each particle adjusts its position according to its own experience, as well as the experience of the entire swarm.

Let $\mathrm{x}$ and $\mathrm{v}$ (formulas 1 and 2) denote the position of the particle and its corresponding flight speed in the n-dimensional search space. $\mathrm{Xi}=\left(x_{i 1}, x_{i 2}, \ldots, x_{i n}\right)$ denotes the position of the i-th particle of the population, and $\mathrm{Vi}=\left(v_{i 1}, v_{i 2}, \ldots, v_{i n}\right)$ denotes the velocity of the $\mathrm{i}$-th particle. The best position of the i-th particle and the global best position among all particles are represented as $\mathrm{pi}=\left(p_{i 1}, p_{i 2}, \ldots, p_{i n}\right)$ and $\mathrm{pg}=$ $\left(p_{g 1}, p_{g 2}, \ldots, p_{g n}\right)$, respectively [19].

The evolutionary strategy of the $\mathrm{i}$-th particle is as follows:

$$
\begin{gathered}
v_{i j}^{\tau+1}=w \cdot v_{i j}^{\tau}+c_{1} \cdot r_{1} \cdot\left(p_{i j}^{\tau}-x_{i j}^{\tau}\right)+c_{2} \cdot r_{2} \cdot\left(p_{q j}^{\tau}-x_{i j}^{\tau}\right) \\
x_{i j}^{\tau+1}=x_{i j}^{\tau}+v_{i j}^{\tau}
\end{gathered}
$$

where $\omega$ is the weight coefficient of inertia; $c_{1}$ and $c_{2}$ are constant accelerations; $r_{1}$ and $r_{2}$ are random variables in the range $(0,1) ; v_{t i j}$ and $x_{t i j}$ are the velocity and position of the i-th particle at the $t$-th iteration, respectively.

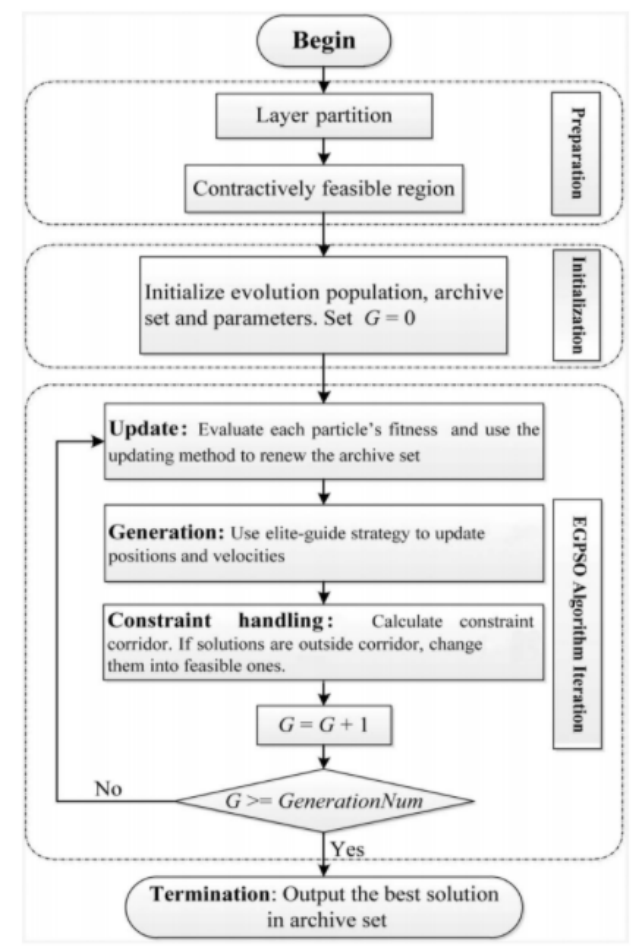

Fig. 2. Algorithm in the swarm optimization method

\section{DEMONSTRATION OF THE COMPLEX OPERATION}

To work with the software package, a number of expenses were taken, corresponding to $90 \%$ of the supply of the Volga River tributary for the Votkinskaya HPP, the hydrograph of which can be obtained from the Rules.

The water management year is divided into 20 accounting periods with a duration of 10 to 31 days, and the year is divided in accordance with the rules for the use of water resources [7].

As the initial information for the calculation, you will need:

- Flow rate with accuracy for each calculation period: $Q_{\text {inf }}(\mathrm{t}), \mathrm{m}^{3}$ per second;

- Connection curves of the upper and lower reaches: $Z_{\text {ub }}\left(V_{\text {storage }}\right), \mathrm{m} ; Z_{\mathrm{lb}}\left(Q_{\mathrm{lb}}\right), \mathrm{m}$;

- Pressure losses on water supply structures: $\Delta \mathrm{h}, \mathrm{m}$;

- Upstream flow loss: $\Delta \mathrm{Q}, \mathrm{m}^{3} / \mathrm{s}$;

- Operating characteristics of the generating units;

- The mark at the beginning of the calculation, determined by the task: $Z_{\mathrm{ub}}, \mathrm{m}$;

- Dispatch schedule of the reservoir;

After performing the calculations according to the algorithm [20], the following results were obtained (Table 1):

TABLE I. REGIME OF VOTKINSKAYA HPP OBTAINED BY COMPLEX

\begin{tabular}{|l|l|l|l|l|l|l|l|}
\hline Period & Inflow & Outflow & Mark & $\begin{array}{c}\text { Mark } \\
\text { low }\end{array}$ & H & $\boldsymbol{N}_{\text {HPP }}$ & $\mathbf{E}_{\text {hpp }}$ \\
\hline Month & $\mathrm{m}^{3} / \mathrm{s}$ & $\mathrm{m}^{3} / \mathrm{s}$ & $\mathrm{m}$ & $\mathrm{m}$ & $\mathrm{m}$ & MWt & $\begin{array}{l}\text { Mln. } \\
\text { kWt.h }\end{array}$ \\
\hline \multirow{2}{*}{ April } & 1372 & 1465 & 85,08 & 66,22 & 18,86 & 246 & 58,93 \\
\cline { 2 - 8 } & 2984 & 1687 & 85,60 & 66,55 & 19,05 & 287 & 68,83 \\
\hline \multirow{3}{*}{ May } & 3370 & 2430 & 86,60 & 67,65 & 18,95 & 415 & 99,57 \\
\cline { 2 - 8 } & 7308 & 5945 & 87,60 & 72,89 & 14,71 & 859 & 206,23 \\
\cline { 2 - 8 } & 5845 & 5049 & 88,45 & 71,55 & 16,90 & 820 & 216,39 \\
\hline \multirow{3}{*}{ June } & 3850 & 2720 & 88,85 & 68,08 & 20,77 & 517 & 124,08 \\
\cline { 2 - 8 } & 3359 & 3084 & 89,00 & 68,63 & 20,37 & 578 & 138,80 \\
\cline { 2 - 8 } & 3537 & 2969 & 89,00 & 68,46 & 20,54 & 560 & 134,51 \\
\hline July & 1509 & 1564 & 89,00 & 66,36 & 22,64 & 320 & 238,42 \\
\hline Aug. & 1166 & 1339 & 88,85 & 66,03 & 22,82 & 277 & 205,80 \\
\hline Sept. & 1104 & 1470 & 88,45 & 66,22 & 22,23 & 296 & 141,88 \\
\hline Oct. & 1086 & 1330 & 88,00 & 66,01 & 21,99 & 264 & 196,65 \\
\hline \multirow{3}{*}{ Nov. } & 1101 & 1303 & 87,65 & 65,98 & 21,67 & 255 & 61,27 \\
\cline { 2 - 8 } & 897 & 1216 & 87,40 & 65,84 & 21,56 & 237 & 56,82 \\
\cline { 2 - 8 } & 1055 & 1011 & 87,25 & 65,54 & 21,71 & 199 & 47,67 \\
\hline Dec. & 739 & 1127 & 86,71 & 65,71 & 21,00 & 214 & 158,96 \\
\hline Jan. & 914 & 850 & 86,21 & 65,30 & 20,91 & 161 & 119,52 \\
\hline Feb. & 806 & 851 & 86,13 & 65,30 & 20,83 & 160 & 107,68 \\
\hline March & 820 & 835 & 85,96 & 65,28 & 20,68 & 156 & 116,09 \\
\hline April & 1308 & 2019 & 85,43 & 67,04 & 18,39 & 328 & 78,70 \\
\hline
\end{tabular}

The calculations were optimized by the swarm method, the results are presented in Table 2:

TABLE II. REGIME OF VOTKINSKAYA HPP OPTIMIZED BY SWARM METHOD 


\begin{tabular}{|c|c|c|c|c|c|c|c|}
\hline Period & Inflow & Outflow & Mark & $\begin{array}{c}\text { Mark } \\
\text { low }\end{array}$ & $\mathbf{H}$ & $N_{\text {HPP }}$ & $\mathbf{E}_{\mathrm{hpp}}$ \\
\hline Month & $\mathrm{m}^{3} / \mathrm{s}$ & $\mathrm{m}^{3} / \mathrm{s}$ & $\mathrm{m}$ & $\mathrm{m}$ & $\mathrm{m}$ & $\mathrm{MWt}$ & $\begin{array}{l}\text { Mln. } \\
\text { kWt.h }\end{array}$ \\
\hline \multirow{2}{*}{ April } & 1372 & 1984 & 85,33 & 66,99 & 18,34 & 321 & 77,02 \\
\hline & 2984 & 1838 & 85,6 & 66,78 & 18,82 & 308 & 73,88 \\
\hline \multirow{3}{*}{ May } & 3370 & 2551 & 86,6 & 67,62 & 18,98 & 432 & 103,69 \\
\hline & 7308 & 6973 & 87,15 & 71,63 & 15,52 & 931 & 224 \\
\hline & 5845 & 5134 & 87,65 & 70,14 & 17,51 & 781 & 206 \\
\hline \multirow{3}{*}{ June } & 3850 & 3009 & 88,35 & 68,14 & 20,21 & 547 & 131 \\
\hline & 3359 & 2999 & 88,85 & 68,13 & 20,72 & 561 & 135 \\
\hline & 3537 & 3537 & 89 & 68,7 & 20,3 & 646 & 155 \\
\hline July & 1509 & 1509 & 89 & 66,31 & 22,69 & 310 & 230,86 \\
\hline Aug. & 1166 & 1360 & 88,75 & 66,09 & 22,66 & 279 & 207,71 \\
\hline Sept. & 1104 & 1302 & 88,34 & 66 & 22,34 & 263 & 126,46 \\
\hline Oct. & 1086 & 1311 & 87,87 & 66,01 & 21,85 & 259 & 192,87 \\
\hline \multirow{3}{*}{ Nov. } & 1101 & 1302 & 87,47 & 66 & 21,47 & 253 & 60,69 \\
\hline & 897 & 1000 & 87,34 & 65,53 & 21,8 & 199 & 47,77 \\
\hline & 1055 & 1100 & 87,27 & 65,55 & 21,6 & 215 & 48,24 \\
\hline Dec. & 739 & 1031 & 86,82 & 65,56 & 21,32 & 198 & 147,62 \\
\hline Jan. & 914 & 980 & 86,29 & 65,53 & 20,78 & 189 & 140,91 \\
\hline Feb. & 806 & 854 & 86,12 & 65,28 & 20,83 & 160 & 107,41 \\
\hline March & 820 & 879 & 85,96 & 65,32 & 20,63 & 164 & 121,67 \\
\hline April & 1308 & 2117 & 85,43 & 67,15 & 18,28 & 341 & 81,86 \\
\hline
\end{tabular}

Due to the many restrictions imposed on each operating mode of the station, it was not possible to obtain a large difference between the direct calculation and the optimized one, it is only 43 million $\mathrm{kWh}$.

\section{CONCLUSION}

The implemented version of the software package for research and calculation of complex hydraulic systems, in the current implemented version, allows to carry out water-energy modes of operation for one of the hydroelectric power stations of the Volga-Kama cascade - Votkinskaya HPP. In its current version, the complex allows to carry out water-energy calculation of the operation mode of the station for one watereconomic year. Currently, this complex is used as a tool for coursework in the Moscow Power Engineering Institute.

\section{REFERENCES}

[1] Order of the Ministry of Education and Science of Russia of November 21, 2014 №1500 "On the approval of the federal state educational standard of higher education in the direction of preparation 13.04.02 electric power and electrical engineering (master's level)".

[2] N.V. Fisher, "Innovative technologies in professional education," Bulletin of the Adyghe State University. Series 3: Pedagogy and Psychology, no. 1, 2010. [Online]. Available: http://cyberleninka.ru/article/n/innovatsionnye-tehnologii-vprofessionalnom-obrazovanii

[3] I. P. Druzhinin, Long-term forecast and information. Novosibirsk: Science, 1987.

[4] Professional standard "Worker for planning the modes of hydroelectric power plants/pumped storage power plants" (approved by order of the
Ministry of Labor and Social Protection of the Russian Federation of March 19, 2015 №173n).

[5] Order of the Ministry of Education and Science of Russia of 03.09.2015 №955 "On the approval of the federal state educational standard of higher education in the direction of preparation 13.03.02 Electrical power engineering and electrical engineering (bachelor's level)".

[6] High-level programming language Python. [Online]. Available: www.python.org

[7] Order of the Federal Agency for Water Resources of 07.11.2015 N 225 "On Approval of the Rules for the Use of Water Resources of the Kama and Votkinsk Reservoirs on the Kama River".

[8] Regulations for the operational dispatch control of the electric power regime of control facilities of the UES of Russia as amended on June 22, 2017 (Minutes No. 14/2017 of the meeting of the Supervisory Board of the NP Market Council Association).

[9] A. Yu. Aleksandrovsky and B. I. Silaev, Hydropower plants: a tutorial. Moscow: Publishing house of MPEI, 2005.

[10] "Educational software package for planning the operation of a hydroelectric power plant," RU Certificate of state registration of the computer program 2019617976, 2019.

[11] W. Jiekang, Z. Jianquan, C. Guotong, and Z. Hongliang, "A Hybrid Method for Optimal Scheduling of Short-Term Electric Power Generation of Cascaded Hydroelectric Plants Based on Particle Swarm Optimization and Chance-Constrained Programming," IEEE Transactions on power systems, vol. 23, no. 4, pp. 1570-1579, 2008.

[12] M. Barros, F. Tsai, S. Yang, J. Lopes, and W. Yeh, "Optimization of Large-Scale Hydropower System Operations," Journal of water resources planning and management, vol. 129, no. 3, pp. 178-188, 2003.

[13] J. P. S. Catalã , S. J. P. S. Mariano, V. M. F. Mendes, and L. A. F. M. Ferreira, "Nonlinear optimization method for short-term hydro scheduling considering head-dependency," European transactions on electrical power, no. 20, pp. 172-183, 2008.

[14] A. Glotić, A. Glotić, P. Kitak, J. Pihler, and I. Tičar, "Parallel SelfAdaptive Differential Evolution Algorithm for Solving Short-Term Hydro Scheduling Problem," IEEE Transactions on power systems. Slovenia, vol. 29, no. 5, pp. 2347-2357, 2014.

[15] M. Azizipour, V. Ghalenoei, M. H. Afshar, and S. S. Solis, Optimal Operation of Hydropower Reservoir Systems Using Weed Optimization Algorithm. USA: Springer Science+Business Media Dordrecht, 2016.

[16] Yu. Yu. Dyulicheva, Swarm intelligence algorithms and their application for the analysis of educational data, 2019.

[17] W. Niua, Z. Feng, C. Cheng, and X. Wu, "A parallel multi-objective particle swarm optimization for cascade hydropower reservoir operation in southwest China," Applied Soft Computing, vol. 70, pp. 562-575, 2018.

[18] Y. He, J. Zhou, X. Xiang, H. Chen, and H. Qin, "Comparison of different chaotic maps in particle swarm optimization algorithm for long-term cascaded hydroelectric system scheduling," Chaos, Solitons \& Fractals, vol. 42, pp. 3169-3176, 2009.

[19] A. Mahor, V. Prasad, and S. Rangnekar, "Scheduling of Cascaded Hydro Power System: A New Self Adaptive Inertia Weight Particle Swarm Optimization Approach," 2009 Int. Conf., on Advances in Recent Technologies in Communication and Computing, 2019.

[20] A. Yu. Aleksandrovsky and N. Yu. Lobanov, "Development of a methodology for planning electricity generation in the second quarter at hydroelectric power plants of the Volga-Kama cascade," Radioelectronics, Electrical Engineering and Power Engineering, vol. 3, pp. 406-407, 2006. 